\title{
Neuropsychological Treatment of Attention Deficit Disorder in Infancy
}

\author{
Yulia Solovieva $^{1} \&$ Luis Quintanar ${ }^{1}$ \\ ${ }^{1}$ Master in Neuropsychological Diagnosis and Rehabilitation, Faculty of Psychology, Puebla Autonomous \\ University, Mexico \\ Correspondence: Yulia Solovieva, Master in Neuropsychological Diagnosis and Rehabilitation, Faculty of \\ Psychology, Puebla Autonomous University, 4 Sur 104, Centro, 72000, Mexico. Tel: 52-222-242-5370. E-mail: \\ yulia.solovieva@correo.buap.mx
}

$\begin{array}{cc}\text { Received: March 18, } 2017 & \text { Accepted: May 26, } 2017 \quad \text { Online Published: August 27, } 2017 \\ \text { doi:10.5539/ies.v10n9p99 } & \text { URL: https://doi.org/10.5539/ies.v10n9p99 }\end{array}$

\begin{abstract}
The syndrome of attention deficit disorder is one of the most frequent pictures of disabilities in pre-scholars. The present study analyses the results of fulfillment of tasks for mechanisms of control and spatial functions. 14 pre-scholars with attention deficit disorder took part in the study. The neuropsychological evaluation was applied before and after application the correction program. The most significant differences were obtained for the functions of voluntary regulation and spatial functions. The program of neuropsychological correction was elaborated and applied 64 sessions. The main goals of the program were to form the action of material external control by introducing activity of role games. The program included orientation in games, perception, spatial relations and solving problems at the level of concrete actions and concrete images and drawing. The results of final neuropsychological evaluation pointed out significant differences between initial and final evaluation for functions of regulation and spatial functions. The comparison of initial and final assessment shows the disappearance of difficulties in some tasks. The discussion establishes positive effects of neuropsychological correction without medication. The results permit to complete the comprehension of the syndrome and propose the original treatment according to the concept of central mechanisms considered in neuropsychology.
\end{abstract}

Keywords: attention deficit disorder, developmental disabilities, neuropsycological treatment, qualitative neuropsychology, child neuropsychology, treatment of attention in infancy

\section{Introduction}

The syndrome of attention deficit disorder with hyperactivity (ADDH) is one of the most known clinic pictures in pre-scholars (Cohen, 1993; Barkley, 1998; Santana, Paivia, \& Lustenberger, 2003). Frequently, learning disabilities in primary school are related to this syndrome. Recent research tries to discover the mechanisms and causes of the syndrome of attention deficit disorder. Genetic, prenatal and postnatal pathologies, neurobiological, anatomic, neurophysiological and social factors can be mentioned among these causes (Barkley, Grodzinzky, \& DuPaul, 1992; Osipova \& Pankratova, 1997; Pineda \& Roselli, 1997; Zavadenko, 2000).

More recently it has been pointed out the possible participation of subcortical structures (Hoogman, et al, 2017). Nevertheless, it is difficult to find unanimous opinion between specialists in relation with mechanisms and causes of the syndrome (Pineda \& Rosseli, 1997; Solovieva et al., 2013).

Some authors (Valdizán, Navascués, \& Sebastián, 2001) have reported the spectral characteristics of the EEG in children with ADDH, both at rest and during the performance of care tasks, reporting EEG latency in the anterior areas. Others (Satterfield, Schell \& Nicholas, 1994; Idiazábal et al., 2002) have reported an increment in latency of P300 in children with ADDH.

Machinskaya and Krupskaya (2001) studied 7- and 8-year-old children with ADDH and discovered two types of deviations in brain functional status. The first one is related to a functional immaturity of the frontal thalamic system and the second with a decrease in nonspecific activation of the ascending activating reticular formation. The neuropsychological analysis of the cognitive processes in these children showed that this immaturity of the regulatory systems has specific effect on the organization of child's activity.

In last years, neuropsychological evaluation has become a part of analysis of causes of the ADDH. Some authors mention that the definite mechanism is related to insufficiency in executive functions and to prefrontal orbital cortical zone (Lou, et al, 1989; Zametkin, et al., 1990; Hynd, et al., 1990; Fuggetta, 2006; Thorell \& Wahlstedt, 
2006; Barkley, 2013). One of the actual goals of child neuropsychology is to specify the causes that produce the clinical picture of ADDH.

However, the diagnosis of syndrome of ADDH does not show true mechanisms of the defects. Such term seems to be too general and doesn't permit to differentiate specific cases of children who present any kind of motor problems or hyperactivity on the bases of brain damage. Such situation is a grate obstacle for election of adequate methods for correction (Semionova, 1997; Quintanar et al., 2001; Solovieva \& Quintanar, 2015).

Previous neuropsychological studies showed that the most frequently affected brain mechanisms in children with ADDH are programming and control, kinetic organization of movements and actions and spatial functions (Quintanar, Solovieva, \& Bonilla, 2006; Semrud-Clikeman, 2012). It was shown that in different ages different brain mechanisms might be responsible for children's difficulties. Studies with neuropsychological assessment have pointed out each age has its own specific features. For instance, in pre-school age the clinic picture includes a lot of different symptoms, which may not be reduced to only one brain mechanism.

These symptoms include difficulties with programming and control, kinetic organization of movements, spatial functions (analysis and synthesis) and the level of general cortical activation of activity. Participation of spatial functions was really an interesting point, because these difficulties are not usually noticed in children with ADDH diagnosis (Machinskaya \& Krupskaya, 2001; Machinskaya \& Semenova, 2004; Quintanar, Solovieva, \& Bonilla, 2006; Gitten et al., 2006). Such functional deficits conduct to low level of voluntary activity, to absence of psychological readiness for school and of developed graphic actions. This clinical constellation of difficulties is typical and was described in 25 Mexican and 25 Russian pre-scholars in comparison with same quantity of normal children of same age (Solovieva et al., 2013).

From this point of view, the methods of correction have to correspond to the mechanisms observed during neuropsychological evaluation. An example of such an approach can be the program of correction proposed by Pilayeva and Akhutina (2012). The authors analyze the participation of frontal lobes in the syndrome and the elaborated methods are directed to development of functions of programming and control. Special exercises are based in constant orientation and helping during interaction between psychologist and a child. The purpose of the method is to achieve gradual formation of self-programming as a fundamental function of attention in a child. The authors associate programming and control, as components of functioning of frontal lobes, to the syndrome of attention deficit disorder.

Salmina and Filimonova (2001) based their program of correction of voluntary activity on the usage of organized games with different levels of complexity. The term of voluntary activity might be related to diagnosis of attention deficit disorder, but it is difficult to differentiate this term of the cases of absence of psychological readiness for school learning.

Usually, recommendations from the cognitive and behavioral point of view refer to organization of daily life through medication with methylphenidate (Sell-Salazar, 2003; Grund et al., 2006) and isolated tasks for actions with movements. The most frequent methods contain repetition, communicative stimulation and behavioral regulation (Cohen, 1993; Brueckner y Bond, 1995; Reynolds \& Fletcher, 1997). The discussion about real effects of such methods is very strong and it is difficult to found unanimous opinion (Sonuga-Barke et al., 2006; Chacko et al., 2017).

Taking in the account such a situation, it seems useful to show some possibility of functional changes after applied procedures of neuropsychological correction.

The objective of the present study is to show the effects of neuropsychological correction on functioning of some neuropsychological factors applied to pre-school Mexican children with ADDH. The program is based on weak neuropsychological factors observed during initial neuropsychological evaluation. We stress that we have selected very punctual tests and kind of functional difficulties, which are extremely typical for pre-school age.

\section{Method}

The study was of qualitative nature based on ideas of cultural and historical psychology and neuropsychology. Our study is a description of clinic manifestations of functional difficulties presented by children with diagnosis of ADDH before and after participation in the program of neuropsychological correction. Qualitative neuropsychological assessment was carried out during initial and final evaluation. The goal of neuropsychological assessment was to characterize changes in weak mechanisms of brain functioning according to systemic and functional analysis, as proposed by Luria's qualitative neuropsychological approach (Luria, 1973; Akhutina, 2001; Quintanar \& Solovieva, 2003). No kinds of statistic or psychometric tests were applied for the assessment. The program was created and applied on the basis of the conception of interaction between adult and 
child and the zone of proximate development (Vigotsky, 1995; Solovieva \& Quintanar, 2015).

\title{
2.1 Participants
}

The group of pre-scholars was conformed for 14 children with diagnosis of attention deficit disorder $(\mathrm{N}=14)$ according DSM-IV (2000). The age of the children was from 5 to 6 years and the average age 5.27.

All children assisted third grade of urban kinder gardens of the city of Puebla, Mexico. The inclusion criteria were: a) to have an age range of 5.0 months to 6.0 months; B) not have deficiencies in hearing, vision, severe retardation in language development, cerebral palsy, epilepsy, autism or psychiatric disorders, established by the medical history; c) present problems of behavior, impulsivity and attention both in the school and in their family environment; d) have submitted all of the above for a period of not less than 6 months prior to the study; e) possess the characteristics described by the DSM-IV; and e) having been diagnosed with ADDH by the pediatric neurologist.

\subsection{Assessment}

The Brief Neuropsychological child assessment created according to linguistic features of Spanish language and psychological features of pre-scholars has been applied for initial and final evaluation (Solovieva \& Quintanar, 2013). The Scheme bases on Luria neuropsychological approximation for diagnostics and the methods of neuropsychological assessment in children (Luria, 1977; Akhutina, 1997; Akhutina et al., 1996; Quintanar \& Solovieva, 2003).

In this study we report results of initial and final assessment for essential mechanisms identified for clinical picture of $\mathrm{ADDH}$, such are programming and control and spatial functions of synthesis and analysis. These tasks are the most sensitive and significant for determination of weak and strong mechanisms in cases of attention deficit disorder at pre-school age (Solovieva et al, 2013). The tasks for assessment of the functioning of neuropsychological brain mechanisms of programming and control included the following items: manual coordination, coordination of fingers, copy and continuation of graphic sequence (example 1) and verbal conflictive task (example 2) presented in form of a game.

In the verbal conflictive task, the child has to make one heat on the table if he or she hears the word "red" and to make two heats on the table if he or she hears the word "white".

Example 1.

\section{Graphic sequence}

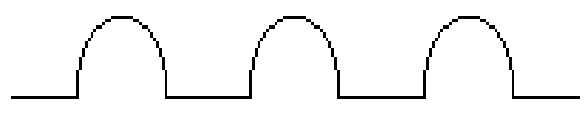

Example 2.

\section{Verbal conflictive task}

The hills are covered with white snow.

The boy plays with red bole.

\author{
In the morning the sky is blue.
}

The girl has the red bowl.

\section{The flowers in the vase are white and red.}

The tasks for assessment of spatial functions include copy of the house (example 3) and free drawing of boy and girl. 
Example 3.

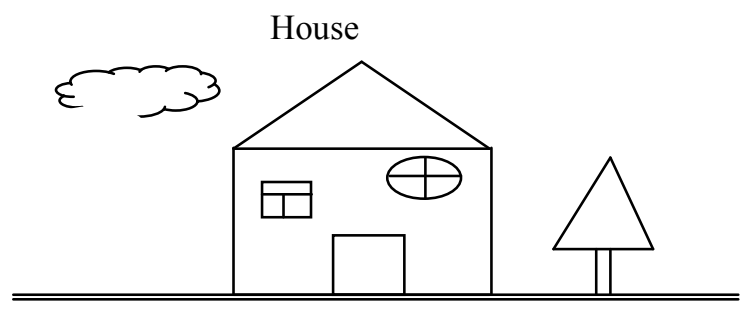

The fulfillment of the tasks receive the qualification from 1 to $4: 1=$ correct execution; 2 = execution with self-correction; 3 = execution with mistakes without self-correction; 4 = impossibility of execution.

\subsection{Procedure}

The children were submitted to initial and final neuropsychological evaluation and to a program of correction during 4 months. The evaluation was individual and took 1 session of 50 minutes.

The program of correction consisted of 4 sessions per week: 3 individual and 1 group sessions of 3 or 4 children. The program was applied in a total of 64 sessions.

\subsection{Program of Correction}

The correction of neuropsychological program was created according to principles of graduate formation of mental actions (Galperin, 1995; Talizina, 2000) and the concept of the zone of proximate development (Vigotsky, 1991; Obukhova, 1995; Solovieva \& Quintanar, 2016a). This means that all the tasks were always interactive and were fulfilled as jointed actions between adult and child and were fulfilled as external actions with inclusion of concrete objects (toys) and images (pictures). The usage of concrete objects and toys means working on the level of material actions and was used as the first step of the program. The level of the work with pictures means perceptive level and was used as the second step of the programme (Solovieva, 2014).

The main goals of the program were to establish the regulation of the activity of children by external language of adult and to form the activity of role games (Elkonin, 1986; Solovieva \& Quintanar 2012, 2016b). The secondary goals were to form orientated perception, graphic activity, and spatial orientation and to establish bases for future intellectual activity as important aspect of preparation for learning at school (Solovieva \& Quintanar, 2013, 2015).

The basic methods of the program were different kinds of games organized and directed by psychologist. Different exercises with concrete objects and concrete images, directed conversation, tasks for classification, correspondence and tasks for conformations of series of objects and images, games with special instructions, production of pictures of concrete objects and different kinds of activities were included in the program (Solovieva \& Quintanar, 2016a, b).

Let us show some concrete examples of the tasks. The goals of all tasks were provided by an adult and followed by a child. For example, before starting the tasks of classification, the basis for classification were explained and shown to the child. Such basis for classification might be as follows: according to some kind of external features (shape, size, and color) of objects and toys. Another possibility for classification was the functional usage of objects. For example, a possible classification might be: let's find the objects, which we use in the kitchen; let's put together all the toys, which we might bring to the beach and so on. Finally, the simplest kind of categorical classification was also used. For example, the child had to separate groups of vegetables and fruits, group of domestic animals, group of means of transportation and so on. At different sessions, the basis for classification were changed and explained with all details to the child.

Special actions with the objects were used in order to provide the possibility for classification according to spatial features and location of object and toys (to your right, above, in the middle of, and to my left and so on). In case of such classification, the adult proposed to move or place some objects in relation to the other objects and explained verbally all the changes to the child. Such kind of tasks for classification was used especially for treatment of understanding and selection of proper spatial relations between objects.

Within the games representation of accessible social roles were used. The animated toys were used as roles according to the topics of the game. For example, for the topic "veterinary clinic", the toys were "sick animals", while the child was a "doctor" and psychologist was a "nurse". The topics of the games, the roles and the rules were changes in different sessions (Solovieva \& Quintanar, 2015). 
During the work with the program, the children obtained little concrete tasks for homework. All tasks were practiced during sessions with psychologist before those were given as home tasks.

Sessions with groups of children included games and other activities used during the whole week in individual sessions.

\section{Results}

The results of the execution of the tasks related to the functioning of the posterior zones of both hemispheres have shown the following. For the majority of the children $(80 \%)$ this task was impossible (table 1). The same phenomenon can be observed in the task of the free drawing of boy and girl (examples 4-6).

Some of the typical characteristics of drawings of children with ADDH are: transparent house (in $57.10 \%$ of the cases), absence of necessary details (in 100\% of cases), difficulties with the distribution of the picture on the paper (in $93.33 \%$ of the cases) and images difficult to recognize (in $42.80 \%$ of cases). These difficulties have also been pointed out by the commitment of the posterior sectors of both cerebral hemispheres (Stiles \& Thal, 1993). The execution could be compared to ones of patients with brain damage in temporal parietal and occipital (TPO) areas.

Table 1. Execution of tasks for spatial functions before and after correction (percentage)

\begin{tabular}{ccccc}
\hline \multirow{2}{*}{ Qualification } & \multicolumn{2}{c}{ Copy of the house } & \multicolumn{2}{c}{ Free drawing } \\
\cline { 2 - 5 } & Before Correction & After Correction & Before Correction & After Correction \\
\hline 1 & 0.00 & 14.28 & 0.00 & 21.42 \\
2 & 0.00 & 21.42 & 0.00 & 21.42 \\
3 & 13.33 & 50 & 20.00 & 35.71 \\
4 & 80.00 & 14.28 & 80.00 & 35.71 \\
\hline
\end{tabular}

Example 4 shows the execution of the task of copy and continuation of graphic sequence by two subjects before and after correction.

Example 4.

Copy and continuation of graphic sequence by two subjects before and after correction

(Subject C.R.)

Before correction

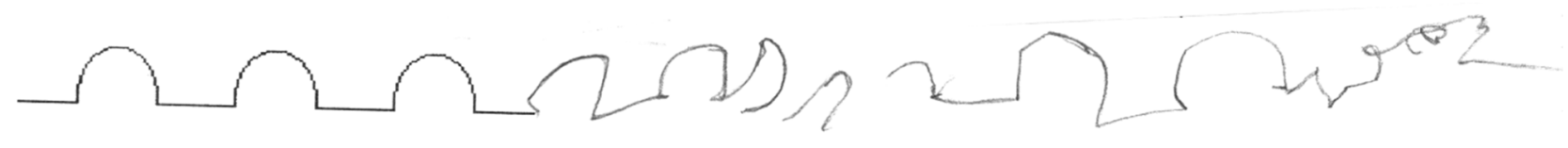

After correction

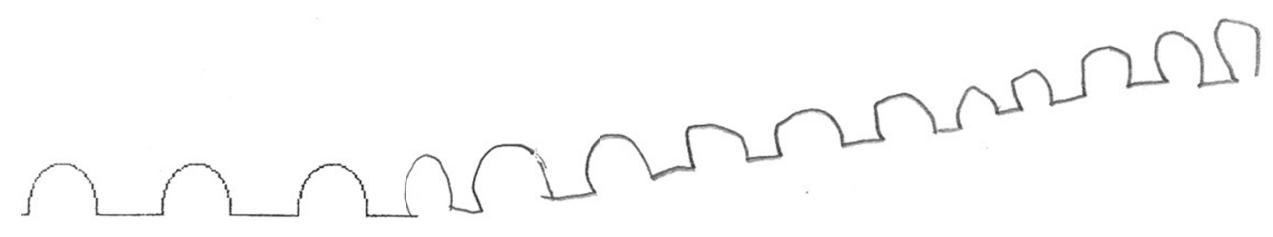

Graphic sequence

(Subject E.F.)

Before correction 


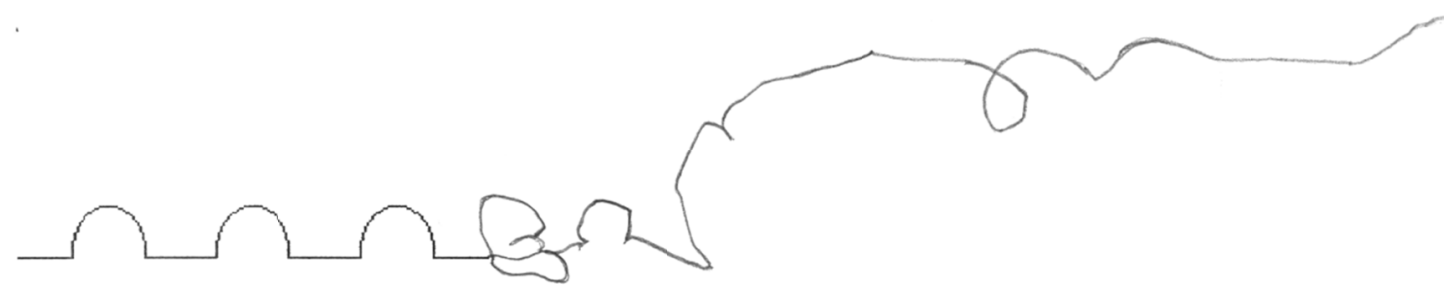

After correction

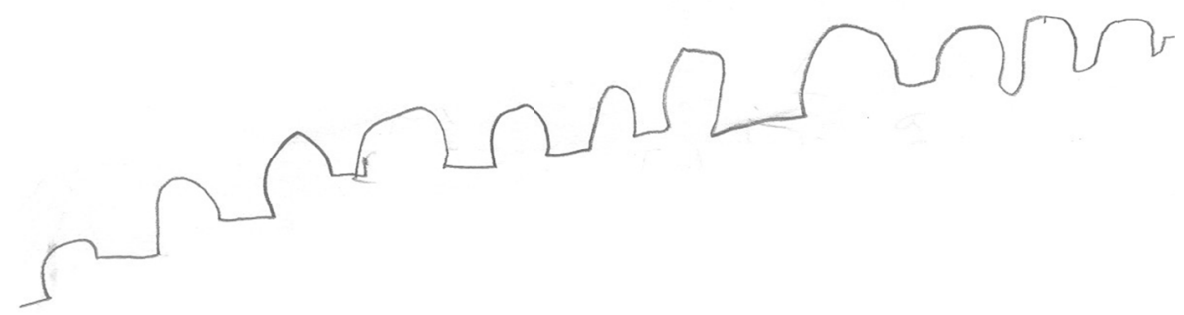

Example 5.

Copy of the house by two subjects before and after correction

(Subject A.K.)

Before correction

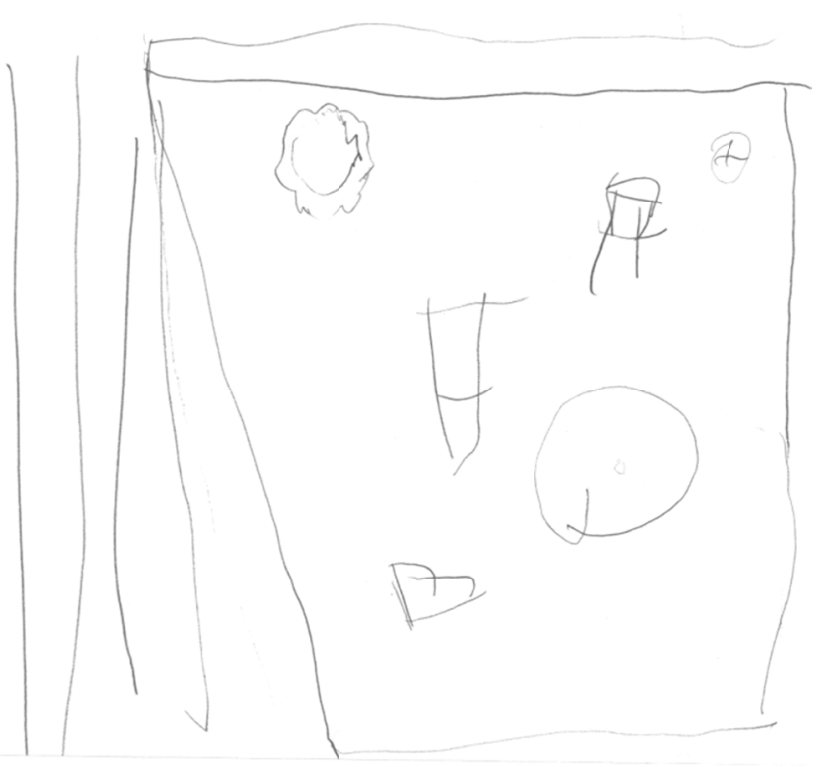


After correction

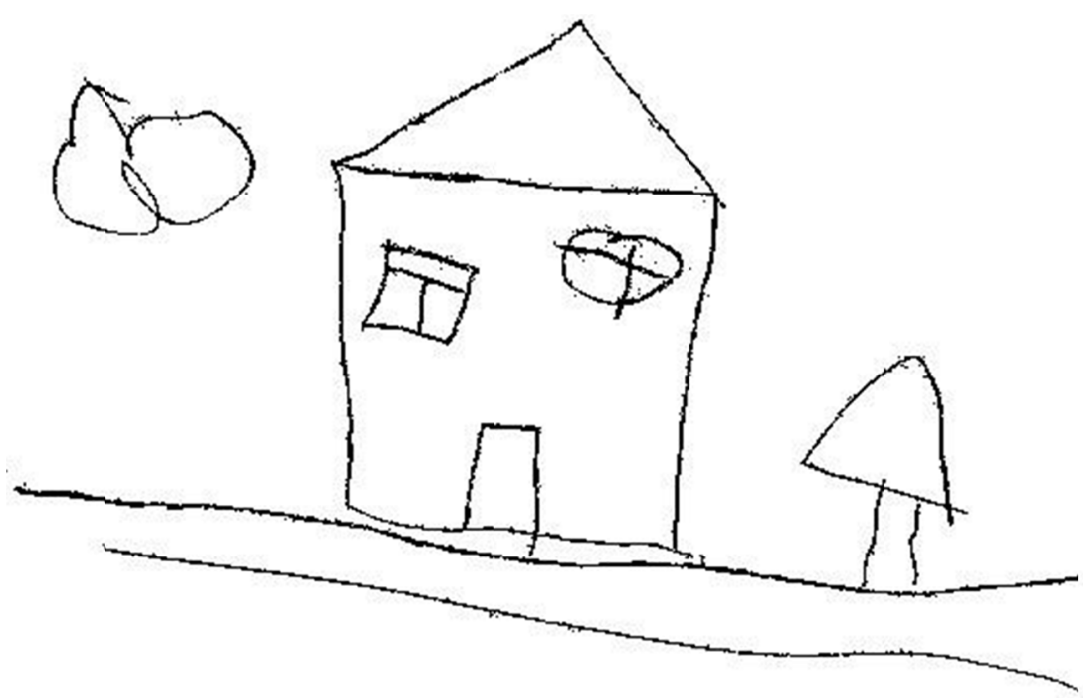

Copy of the house

(Subject B.S.)

Before correction

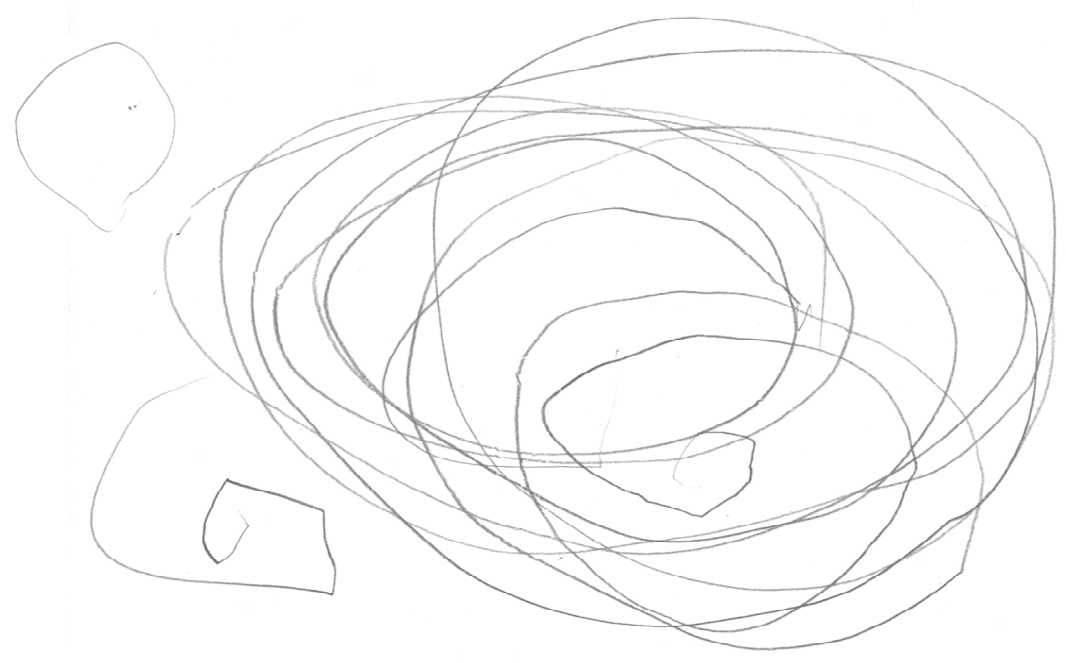

After correction
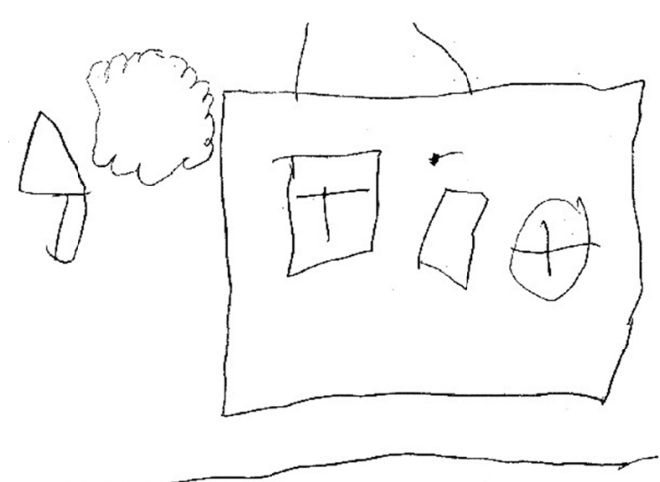


\section{Example 6.}

Free drawing of boy and girl by two subjects before and after correction

(Subject B.S.)

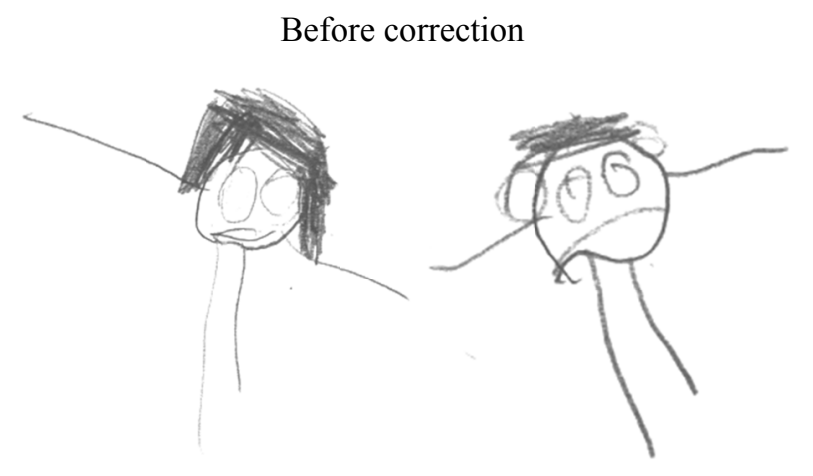

Boy Girl

After correction

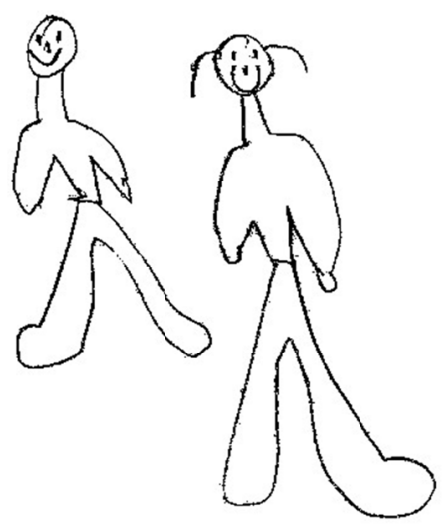

Boy Girl

Free drawing

(Subject A.K.)

\section{Before correction}

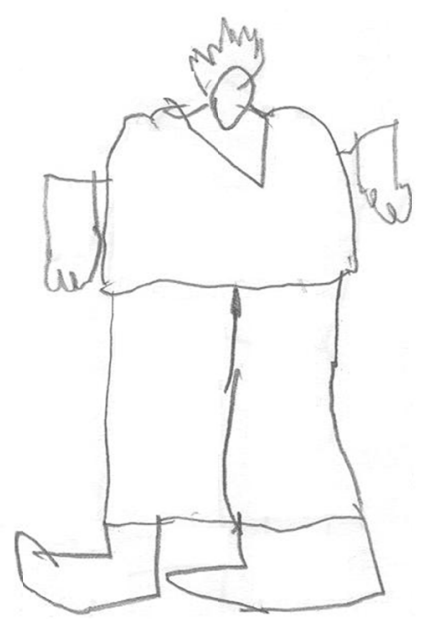

After correction

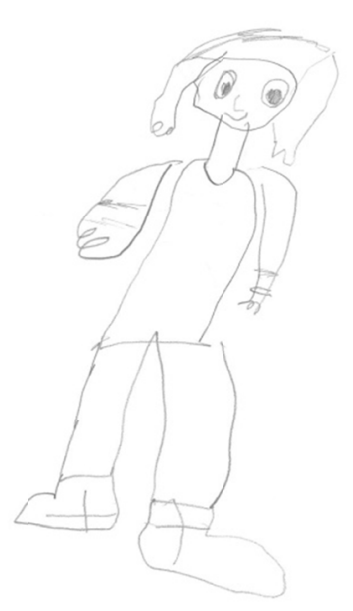

Girl 

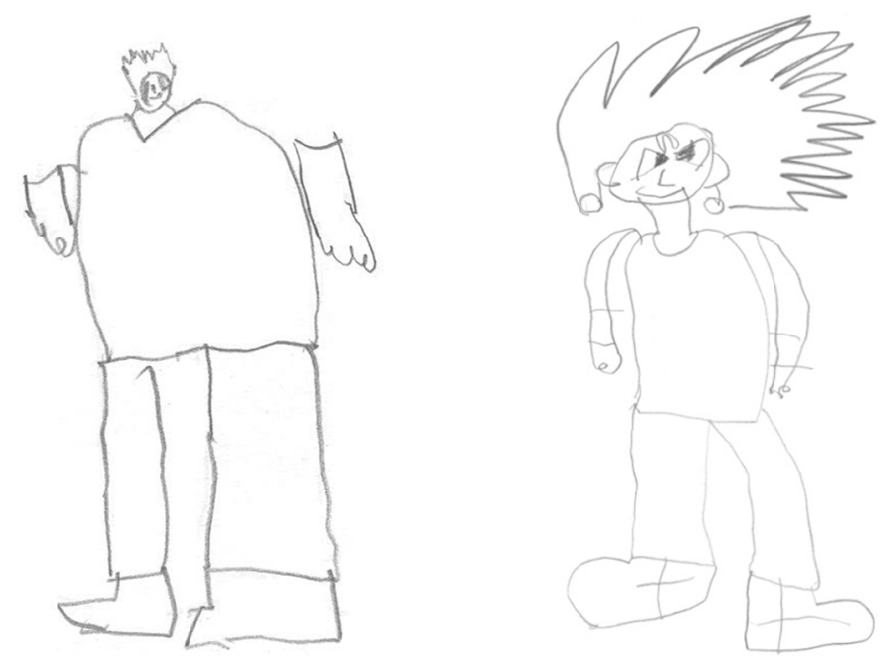

Boy

Table 2 shows the results obtained in initial and final evaluation for the tasks related to factors of programming and control and kinetic organization of actions.

Table 2. Execution of tasks for frontal lobes by children with ADDH before and after correction (in percentage)

\begin{tabular}{|c|c|c|c|c|c|c|c|c|}
\hline \multirow[b]{2}{*}{ Qualification } & \multicolumn{2}{|c|}{ Manual coordination } & \multicolumn{2}{|c|}{ Coordination of fingers } & \multicolumn{2}{|c|}{ Graphic sequence } & \multicolumn{2}{|c|}{ Conflictive task } \\
\hline & $\begin{array}{c}\text { Before } \\
\text { correction }\end{array}$ & $\begin{array}{c}\text { After } \\
\text { correction }\end{array}$ & $\begin{array}{c}\text { Before } \\
\text { correction }\end{array}$ & $\begin{array}{c}\text { After } \\
\text { correction }\end{array}$ & $\begin{array}{c}\text { Before } \\
\text { correction }\end{array}$ & $\begin{array}{c}\text { After } \\
\text { correction }\end{array}$ & $\begin{array}{c}\text { Before } \\
\text { correction }\end{array}$ & $\begin{array}{c}\text { After } \\
\text { correction }\end{array}$ \\
\hline 1 & 0.00 & 28.6 & 7.14 & 64.28 & 0.00 & 14.28 & 7.14 & 7.14 \\
\hline 2 & 21.42 & 35.7 & 35.71 & 14.28 & 21.42 & 21.42 & 0.00 & 42.85 \\
\hline 3 & 21.42 & 7.1 & 21.42 & 14.28 & 7.14 & 35.71 & 14.28 & 21.42 \\
\hline 4 & 57.14 & 28.6 & 35.71 & 7.14 & 71.42 & 28.57 & 78.57 & 28.57 \\
\hline
\end{tabular}

$1=$ correct execution; 2 = execution with self correction;

3 = execution with mistakes without self-correction; 4 = impossibility of execution.

\section{Discussion}

The results obtained in our study show obvious differences in execution of the tasks for functioning of frontal lobes and posterior zones in initial and final evaluation. It is important to stress that it is not possible, according to our data, to reduce difficulties of children with diagnosis of attention deficit disorder only to one brain mechanism.

According to the results, the initial evaluation pointed out severe defects in the tasks related to functioning of frontal lobes and spatial functions. Similar results have been obtained in previous studies (Quintanar, Solovieva $\&$ Bonilla, 2006). At the same time, the analysis of our results has made it possible to elaborate a concrete program for correction built on the principles of gradual formation of weak functional links in the actions included in the guiding activity of the given psychological age. During the development of the program, ideas about the role of the area of proximal development for the organization of education and upbringing (Vigotsky, 1995), about the pre-school activity (Elkonin, 1986), were used (Galperin \& Kabilnitskaya, 1976; Talizina, 2000) and the importance of identifying strong and weak aspects in the functional organization of child activity (Pilayeva, 1998).

In general we consider that the results obtained in our study were positive in relation to the formation of the elements of regulation and control and the kinetic organization of the movements. Thus, in the final assessment the children were able to propose their own game with topic and the goal according to the adult's proposal, to comply with basic instructions and to march according to the rhythm of the paddle. Improvements were observed in the execution of the corrector test, in the analysis of the missing parts of the objects and in the designation of 
present objects.

Frontal lobes and TPO zone represent brain formations of great complexity in their structure and functioning (Luria, 1979, 1982; Luria \& Xomskaya, 1979; Xomskaya, 1987; Manelis, 1999; Korsakova, Mikadze, \& Balashova, 1997). The absence of orientation is one of the main obstacles for normal acquisition of reading (Luria \& Tsvetkova, 1997), mathematics and problem solution at the begging of school age (Tsvetkova, 1972; Kercood, Zentall, \& Lee, 2004; Lucangeli \& Cabrele, 2006).

Space factors are necessary not only for space and corporal orientation, but also for such activities as drawing, writing, reading and mathematics (Luria, 1977; Tsvetkova, 1985; Luria \& Tsvetkova, 1997; Machinskaya \& Semenova, 2007). Last studies have shown that the organization of material on paper depends on appropriate functioning of posterior areas of right hemisphere (Akhutina \& Zolotariova, 2001). According to these data, it is important to prevent learning disabilities in children with ADDH. One of essential ways for such prevention is early neuropsychological assessment and starting of implementation of correction form pre-school age. Qualitative neuropsychological assessment helps not only to "detect" weak aspects of development, but also to find better methods and strategies for corrections and interactions between adult and child.

Functional affectation of frontal lobes and TPO zones observed in children with attention deficit disorder confirm the necessity of elaboration of special programs of correction which has to include development and formation of correspondent neuropsychological factors (Bonilla \& Cols, 2001; Solovieva \& Cols, 2001; Solovieva \& Quintanar, 2015). Our results show the effectiveness of one of such programs.

The complexity of the functional systems that guarantee the formation of different actions such as graphic activity and problem solving, among others, is evident with the reports of the anatomical structures (Lou, et al, 1989; Zametkin, et al, 1990; Hynd, et al, 1990; Fuggetta, 2006; Thorell \& Wahlstedt, 2006; Barkley, 2013; Hoogman, et al, 2017) and the different brain systems involved in ADDH cases (Machinskaya, Lukashevich \& Fishman, 1997; Machinskaya \& Krupskaya, 2001; Machinskaya \& Semenova, 2007).

The contributions of anatomical and electrophysiological studies in cases of ADDH are evident. However, most clinical studies are limited to the description of symptoms and leave unaddressed therapeutic aspects. We believe that it is fundamental to develop correction programs based on qualitative neuropsychological analysis.

Again, our results speak of great possibilities of the application of the qualitative neuropsychological and psychological analysis in the cases of children with ADDH. According to our opinion, this analysis allows us to determine the type of difficulties that are observed in children with greater accuracy. Unlike a purely symptomatic "attention deficit" diagnosis that refers to a single psychological function, neuropsychological analysis allows the identification of the weakest functional links. On the other hand, the deep psychological analysis that is based on the theory of the activity (Leontiev, 2000; Elkonin, 1986) allows characterization of the state of the governing activity, of the diverse actions, as well as the type of external in the children's regulation. Thus, from the neuropsychological point of view, functional weakness was observed in the studied children in the programming and control factors, in the kinetic organization of movements and actions, and in spatial analysis and synthesis.

From the psychological point of view, in the children the role-play was absent, the object actions were carried out at the level of manipulation, the language of the adult didn't fulfill its role of regulation of child's activity, which does not correspond to the level optimal psychological development at pre-school age (Vigotsky, 1995). All of these data significantly enrich the information that specialists can obtain about children who are diagnosed with "attention deficit disorder".

\section{Conclusions}

1) In preschool children with $\mathrm{ADDH}$, tasks that require not only the participation of the prefrontal sectors, but also those tasks that need the work of the later TPO sectors

2) Neuropsychological factors of frontal lobes and TPO participate in the clinic picture of attention deficit disorder.

3) The program of correction, based on guided development of these factors, helps to improve the difficulties.

4) The children show strong improvement of functions of regulation, control and organization of actions.

5) The functioning of the spatial functions needs longer correction.

\section{References}

Akhutina, T. V. (1997). Neuropsychology of individual differences in children as bases for application of 
neuropsychological methods at school. School of Health, 4, 9-17.

Akhutina, T. V. (2001). Neuropsychological approach for the diagnostic and correction of difficulties in learning of writing. In M. G. Jrakovskaya (Ed.), Contemporary approaches for diagnostic and correction of verbal disorders. San-Petersburg: University of San-Petersburg.

Akhutina, T. V., \& Pilayeva, N. M. (2012) Metódica para el desarrollo de la atención en niños preescolares y escolares. Mexico: Autonomous University of Puebla.

Akhutina, T. V., \& Zolotariova, T. V. (2001). About visuo-spatial disgraphy: Neuropsychological analysis and methods of correction. In Yu. Solovieva, \& L. Quintanar (Eds.), Methods of intervention in child neuropsychology. México, Puebla Autonomous University.: 117-146.

American Psychiatric Association. (2000). Diagnostic and Statistical Manual of Mental Disorders. Washington: American Psychiatric Assoc.

Barkley, R. A. (1998). Hipperactivity and attention deficit disorder. Research and Science, 11, 48-53.

Barkley, R. A. (2013). Distinguishing sluggish cognitive tempo from ADDH in children and adolescents: Executive functioning, impairment and comorbidity. Journal of Clinical Child \& Adolescents Psychology, 42(2), 161-173. https://doi.org/10.1080/15374416.2012.734259

Barkley, R. A., Grodzinzky, G., \& DuPaul, G. J. (1992). Frontal lobe functions in attention deficit disorder with and without hiperactivity. A review and research report. Journal of Abnormal Child Psychology, 20(2), 163-188. https://doi.org/10.1007/BF00916547

Bonilla, R., Solovieva, Yu., Figueroa, M., Martínez, J. M., \& Quintanar, L. (2001). Neuropsychological treatment of pre-scholars with attention déficit disorder with impulsivity. In Yu. Solovieva, \& L. Quintanar (Eds.), Methods of intervention in child neuropsychology (pp. 117-146). Mexico: Autonomous University of Puebla.

Brueckner, L. J., \& Bond, G. L. (1995). Diagnóstico y tratamiento de las dificultades en el aprendizaje. La Habana: Editorial Revolucionaria.

Chacko, A., Bedard, C. V., Marks, D., Gopalan, G., Feirsen, N., \& Uderman, J. (2017). Sequenced neurocognitive and behavioral parent training for the treatment of ADHD in school age children. Child Neuropsychology. https://doi.org/10.1080/09297049.2017.1282450

Cohen, R. A. (1993). The Neuropsychology of Attention. New York, Plenum Press. https://doi.org/10.1007/978-1-4419-7463-1

Elkonin, D. B. (1986). Psicología del juego. Madrid: Pablo del Río.

Fuggetta, G. P. (2006). Impairment of executive functions in boys with attention deficit/hyperactivity disorder. Child Neuropsychology, 12(1), 1-21. https://doi.org/10.1080/09297040500203418

Galperin, P. Ya., \& Kobilnitskaya, S. L. (1976). Experimental formation of attention. Moscow: Moscow State University.

Gitten, J. C., Winer, J. L., Festa, E. K., \& Heindel, W. C. (2006). Conditional associative learning of spatial and object information in children with attention deficit/hyperactivity disorder. Child Neuropsychology, 12(1), 39-56. https://doi.org/10.1080/09297040500205579

Grund, T., Lhemann, K., Bock, N., Rothenberger, A., \& Teuchert-Noodt, G. (2006). Influence of methylphenidate on brain development-An update of recent animal experiments. Behavioral and Brain Functions, 2(2), 1-14.

Hoogman, M., Bralten, J., Hibar, D. P., Mennes, M., Zwiers, M. P., Schweren, L. S. J., . . Franke, B. (2017). Subcortical brain volume differences in participants with attention deficit hyperactivity disorder in children and adults: A cross-sectional mega-analysis. The Lancet Psychiatry, 4(2) 1-10. https://doi.org/10.1016/S2215-0366(17)30049-4

Hynd, G. W., Semrud-Clikeman, M., Lorys, A. R., Novey, E. S., \& Eliopulos, D. (1990). Brain morphology in development dyslexia and attention deficit disorder/hyperactivity. Archives of Neurology, 47, 919-926. https://doi.org/10.1001/archneur.1990.00530080107018

Idiazábal, M.-A., Palencia-Taboada, A. B., Sangorrín, J., \& Espadaler-Gamissans, J. M. (2002). Potenciales evocados cognitivos en el trastorno por deficit de atención con hiperactividad. Revista de Neurología, 34(4), 301-305. 
Kercood, S., Zentall, S. S., \& Lee, D. L. (2004). Focusing attention to deep structure in math problems: Effects on elementary education students with and without attentional deficits. Learning and Individual Differences, 14(2) 91-105. https://doi.org/10.1016/j.lindif.2003.09.001

Korsakova, N. K., Mikadze, Yu. V., \& Balashova, E. Yu. (1997). Children with problems in learning: Neuropsychological diagnostic of difficulties in minor school children. Moscow: Russian Pedagogical Agency.

Leontiev, A. N. (2000). Conferencias sobre psicología general. Moscú, Sentido.

Lou, H. C., Henriksen, L., Bruhn, P., Borner, H., \& Neilson, J. B. (1989). Striatal Dysfunction in attention deficit and hyperkinetic disorder. Archives of Neurology, 46, 48-52. https://doi.org/10.1001/archneur.1989.00520370050018

Lucangeli, D., \& Cabrele, S. (2006). Mathematical difficulties and ADHD. Exceptionality, 14(1), 53-62. https://doi.org/10.1207/s15327035ex1401_5

Luria, A. R. (1973). Introduction to neuropsychology. Moscow: Moscow State University.

Luria, A. R. (1977). Superior cortical functions of man. La Habana: Orbe.

Luria, A. R. (1979). Language and conscience. Moscow: Moscow State University.

Luria, A. R. (1982). The role of language in development of behavior. Mexico: Cartago.

Luria, A. R., \& Tsvetkova, L. S. (1997). Neuropsychology and learning disabilities at normal school. Moscow: Academy of Pedagogical and Social Science.

Luria, A. R., \& Xomskaya, E. D. (1979). Frontal lobes and regulation of psyquic processes. Moscow: Moscow State University.

Machinskaya, R. I., \& Krupskaya, E. V. (2001). EEG Analysis of the functional state of deep regulatory structures of the brain in hyperactive seven to eight-year-old children. Human Physiology, 27(3), 368-70. https://doi.org/10.1023/A:1010938426006

Machinskaya, R. I., \& Semenova, O. A. (2004). Peculiarities of formation of the cognitive functions in junior school children with different maturity of regulatory brain systems. Journal of Evolutionary Biochemistry and Physiology, 40(5), 528-538. https://doi.org/10.1007/s10893-005-0009-3

Machinskaya, R. I., \& Semenova, O. A. (2007). The role of brain regulatory systems in cortex functional organization and information processing development in primary school children. Psychophysiology, 44(Suppl. 1), 100.

Machinskaya, R. I., Lukashevich, I. P., \& Fishman, M. N. (1997). Dynamics of brain electrical activity in 5- to 8-year-old normal children and children with learning difficulties. Human Physiology, 23, 517-522.

Manelis, N. G. (1999). Neuropsychological regularities in normal development. School of Health, 1, 8-25.

Obujova, L. F. (1995). Child Psychology. Moscow: Trivoli.

Osipova, E. A., \& Pankratova, N. V. (1997). The dynamic of neuropsychological status in children with different variants of manifestation of the syndrome of attention deficit disorder and hiperactivity. School of Health, 4, $34-43$.

Pilayeva, N. M. (1998). Neuropsychological help for children in groups for correction and development. In E. D. Xomskaya, \& T. V. Akhutina (Eds.), I International Conference dedicated to the memory of A.R. Luria (pp. 238-243). Moscow: Moscow State University.

Pilayeva, N. M., \& Akhutina, T. V. (1997). School of attention. Moscow: Inter.

Pineda, D., \& Rosselli, M. (1997). Hiperactivity and attentional deficit. In M. Rosselli, A. Ardila, D. Pineda, \& F. Lopera (Eds.), Child Neuropsychology (pp. 253-278). Advance in Research, Theory and Practice. Medellín, Prensa Creativa.

Polonskaya, N. N., \& Yablokova, L. V. (1998). Functions of programming and control and success in learning during the first school year. In E. D. Xomskaya, \& T. V. Akhutina (Eds.), I International Conference dedicated to the memory of A.R. Luria (pp. 231-237). Moscow: Moscow State University.

Quintanar, L., \& Solovieva, Yu. (2003). Manual de evaluación neuropsicológica infantil. Mexico: Autonomous University of Puebla.

Quintanar, L., Hernández, A., Bonilla, R., Sánchez, A., \& Solovieva, Yu. (2001). Function of regulation of 
language in children with attention deficit disorder. Journal of Thinking and Language of Latin America, 9(2), 164-180.

Quintanar, L., Solovieva, Yu, \& Bonilla, R. (2006). Analysis of Visuospatial Activity in Preschool Children with Attention Deficit Disorder. Human Physiology, 32(1), 51-55. https://doi.org/10.1134/S0362119706010063

Reynolds, R. C., \& Fletcher-Janzen, E. (1997). Handbook of Clinical Child Neuropsychology. New York: Plenum Press. https://doi.org/10.1007/978-1-4757-5351-6

Salmina, N. G., \& Filimonova, O. G. (2001). Diagnostico y corrección de la actividad voluntaria en niños preescolares y escolares. Mexico: Autonomous University of Tlaxcala.

Santana, R., Paivia, H., \& Lustenberger, I. (2003). Trastorno por deficit de atención con hiperactividad. Montevideo: Printer.

Satterfield, J. H., Schell, A. M., \& Nicholas, T. W. (1994). Preferential neural processing of attended stimuli in attention-deficit hyperactivity disorder and normal boys. Psychophysiology, 31, 1-10. https://doi.org/10.1111/j.1469-8986.1994.tb01018.x

Sell-Salazar, F. (2003). Síndrome de hiperactividad y déficit de atención. Revista de Neurología, 37(4), 353-358.

Semenova, O. A. (1997). Some particularities of motor functions and audio-visual memory in children with slight brain dysfunction. School of Health, 4, 44-48.

Semrud-Clikeman, M. (2012). The role of inattention on academics, fluid reasoning and visual-spatial functioning in two subtypes of ADHD. Applied Neuropsychology: Child, 12(1), 18-29. https://doi.org/10.1080/21622965.2012.665766

Solovieva, Yu. (2014). La actividad intelectual en el paradigma histórico-cultural. Mexico: CEIDE.

Solovieva, Yu., \& Quintanar, L. (2012). Drawing activity as a method for preparation for school. Clinical and Special Psychology, 4, 1-27.

Solovieva, Yu., \& Quintanar, L. (2013). Brief neuropsychological child assessment. Mexico: Puebla Autonomous University.

Solovieva, Yu., \& Quintanar, L. (2015). Games as a method of neuropsychological correction in preschool children with ADDH. British Journal of Education, Society and Behavioral Science, 11(1), 1-14. https://doi.org/10.9734/BJESBS/2015/19124

Solovieva, Yu., \& Quintanar, L. (2016a). The role of zone of proximate development in interactive assessment of intelectual development. British Journal of Education, Society \& Behavioural Science, 14(1), 1-11.

Solovieva, Yu., Gonzáles, C., \& Quintanar, L. (2016b). Developmental analysis of symbolic perceptual actions in preschools. British Journal of Education, Society \& Behavioural Science, 15(3), 1-13.

Solovieva, Yu., Machinskaya, R., Quintanar, L., Bonilla, R., \& Pelayo, H. (2013). Neuropsicología y electrofisiología del TDA en la edad preescolar. Mexico: Autonomous University of Puebla.

Sonuga-Barke, E. J. S., Thompson, M., Abikoff, H., Klein, R., \& Miller, L. B. (2006). Nonpharmacological interventions for preschools with ADHD. Infants \& Young Children, 19(2), 142-153. https://doi.org/10.1097/00001163-200604000-00007

Stiles, J., \& Thal, D. (1993) Linguistic and spatial cognitive development following early focal brain injury: Patterns of deficit and recovery. Brain and Cognition. Cambridge: Mass.

Talizina, N. F. (2000). Handbook of pedagogical psychology. Mexico: Autonomous University of San Luis Potosi.

Thorell, L. B., \& Wahlstedt, C. (2006). Executive functioning deficits in relation to symptoms of ADHD and/or ODD in preschool children. Infant and Child Development, 15, 503-518. https://doi.org/10.1002/icd.475

Tsvetkova, L. S. (1972). Rehabilitation in cases of brain local damage. Moscow: Moscow State University.

Valdizán, J. R., Navascués, M. A., \& Sebastián, M. V. (2001). Cartografía cerebral y trastorno por déficit de atención con hiperactividad. Revista de Neurología, 32(2), 127-132.

Vigotsky, L. S. (1995). Obras Escogidas, Tomo III. Madrid: Visor.

Xomskaya, E. D. (1987). Neuropsychology. Moscow: Moscow State University.

Zametkin, A. J., Nordahl, T. E., Gross, M., King, A. C., Semple, W. E., Rumsey, J., . . Cohen, R. M. (1990). 
Cerebral glucose metabolism in adults with hyperactivity of childhood onset. New England Journal of Medicine, 323, 1361-1366. https://doi.org/10.1056/NEJM199011153232001

Zavadenko, N. N. (2000). How to understand the child: children with hiperactivity and attention deficit disorder? Moscow, Medical and Psychological Pedagogy.

\section{Copyrights}

Copyright for this article is retained by the author(s), with first publication rights granted to the journal.

This is an open-access article distributed under the terms and conditions of the Creative Commons Attribution license (http://creativecommons.org/licenses/by/4.0/). 